\title{
The use of patch testing for the diagnosis of contact dermatitis: An Albanian experience
}

\author{
Monika Fida1* , Geriolda Topi², Etleva Qirko³, Suela Kellici², Erjona Shehu , Orjana Dervishi , \\ Ermira Vasili ${ }^{1}$
}

${ }^{1}$ Department of Dermatology, Faculty of Medicine, Medical University of Tirana, Tirana, Albaniaq, ${ }^{2}$ Medical University of Tirana, Tirana, Albania, ${ }^{3}$ Department of allergology and Immunology, Medical University of Tirana, Albania

\begin{abstract}
Introduction: The daily increase of using chemical, aromatic and cosmetic products has been associated with significant increase in frequency of skin diseases such as eczemas and contact dermatitis (CD). The aim of this study was to evaluate the use of patch testing (PT) for the diagnosis of CD and provide current data on the frequency of sensitization to various contact allergens among patients with $C D$ in the Albanian population.
\end{abstract}

Methods: We retrospectively analyzed all consecutive patients clinically suspected for CD during the period February 2010 - February 2011, in the outpatient setting. PT was done using Baseline European Series consisting of 31 allergens. Risk factors (age, gender, occupation and place of residence) and sensitization to various contact allergens were evaluated.

Results: In total, 193 patients clinically suspected for CD were included in the study and underwent PT. The highest prevalence of CD was found in the age-group of 31-40 years (32.6\%), with a statistically significant difference between other age-groups $\left(x^{2}=141.2, p<0.01\right)$. Positive PT results with at least one allergen were seen in 144 (74.6\%) patients suspected for CD. The two most common allergens were nickel and potassium dichromate. Construction worker and hairdresser were the most affected professions. Females had a chance of 1.8 times higher for having a positive patch test result compare to males $(\mathrm{OR}=1.8 ; 95 \% \mathrm{Cl} 0.91-3.39)$.

Conclusion: Determination of allergens that cause contact dermatitis is a necessity not only to confirm the correct diagnosis, but also for the qualitative treatment and prevention of the disease. Patch testing, even though an old method, still remain a valuable and non-invasive approach to determine the causes of contact dermatitis.

Key words: contact dermatitis; patch testing; allergens; potassium dichromate; nickel;

*Corresponding author: Monika Fida, Department of Dermatology, Faculty of Medicine, Medical University of Tirana; Rr. e Dibrës, 371, 1005, Tirana, Albania; Phone: +355 67206 2559; E-mail: monikafida@yahoo.co.uk

Submitted: 03 February 2015 / Accepted: 28 June 2015

DOI: http://dx.doi.org/10.17532/jhsci.2015.227

\section{INTRODUCTION}

The daily increase of using chemical, aromatic and cosmetic products has been associated with a significant increase of frequency of skin diseases such as eczemas and contact dermatitis $(1,2)$. Today, contact dermatitis (CD) is a very common pathological condition, closely related to profession, with 
a high prevalence and a high impact on quality of life (3-5). It is defined as an inflammatory reaction of the skin caused by different allergens and irritating substances (6).

The development of contact dermatitis has been related to a combination of individual characteristics (endogenous factors) and exposure (exogenous factors) $(6,7)$. Skin contact with allergen or irritating substance is a necessary step for development of CD. However, the probability of occurrence and the degree of reaction depend on the type of allergen or irritant and intensity of the exposure (7). Even though the effect of chemical irritants can be reduced by precautions (limiting the contact with these materials or using appropriate protection), the sensitivity to various substances is increasing $(8,9)$. This makes the prevention and medical treatment of contact dermatitis very difficult $(10,11)$. Nevertheless, accurate application and correct interpretation of patch tests (PT) are considered the key for a successful treatment of contact dermatitis $(12,13)$.

According to literature data, the median prevalence of $\mathrm{CD}$ in the general population to at least one allergen was $21.2 \%$ (range $12.5-40.6 \%$ ) (14). Likewise, the prevalence of hand eczema in the general population is estimated around $4 \%$, with lifetime prevalence around 15\% (15). However, most of the data published are extrapolated from surveillance studies on occupational dermatitis. According to these studies, the annual incidence of contact dermatitis is 13 to 34 cases per 100.000 workers $(16,17)$.

Very little is known about the distribution of CD among Albanian population and to our knowledge no recent data has been published. Thus, we aimed to evaluate the use of PT for the correct diagnosis of $\mathrm{CD}$ and provide current data on the frequency of sensitization to various contact allergens. Furthermore, we evaluated the distribution of risk factors, such were age, gender, occupation and place of residence in a group of Albanian patients.

\section{METHODS}

\section{Study design}

We retrospectively analyzed all consecutive patients clinically suspected for CD during the period February 2010 - February 2011 at the outpatient unit of Polyclinic "At Luigji Monti" in Tirana. Medical history and clinical diagnosis were recorded using two questionnaires adapted for our population in accordance with European standardized questionnaires for skin diseases (18). Questionnaires included information about age, gender, place of residency, profession, exposure to allergens, results of patch testing, spread of the disease, comorbidities and smoking history. Geographical distribution of the patients was totally random.

\section{Study population}

All the patients included in the study were clinically suspected for CD. Before the application of PT the patients had no active disease and were not taking any medication such as corticosteroids (locally or systemic) and/or immunomodulatory drugs. Clinically healthy individuals and pregnant women were excluded from the study. Informed consent was acquired from all subjects. Risk factors, such as age, gender, place of residence (rural or urban) and profession were investigated in this group of patients. PT results were compared between males and females and also between age-groups. The diagnosis of CD for each patient was made based on a detailed medical history, occupation profile, characteristics of skin lesions and PT results.

\section{Patch testing}

Baseline European Series consisting of 31 allergens (19) were applied to all patients that were clinically suspected for CD. Interpretation of the results was performed after 48 (first reading) and 72 hours (second reading) according to the International Contact Dermatitis Research Group as follow: negative reaction (-); uncertain reaction (?); weak positive reaction $(+)$; strong positive reaction $(++)$ and extreme positive reaction $(+++)$ (Figure 1).

\section{Statistical analysis}

All the data were analyzed using SPSS, version 17.0. Categorical variables were presented as numbers (absolute values) and percentages. Fisher's exact test was used to compare categorical variables. The distribution of the sample size was calculated using D' Agostino-Pearson test. Multivariate logistic 


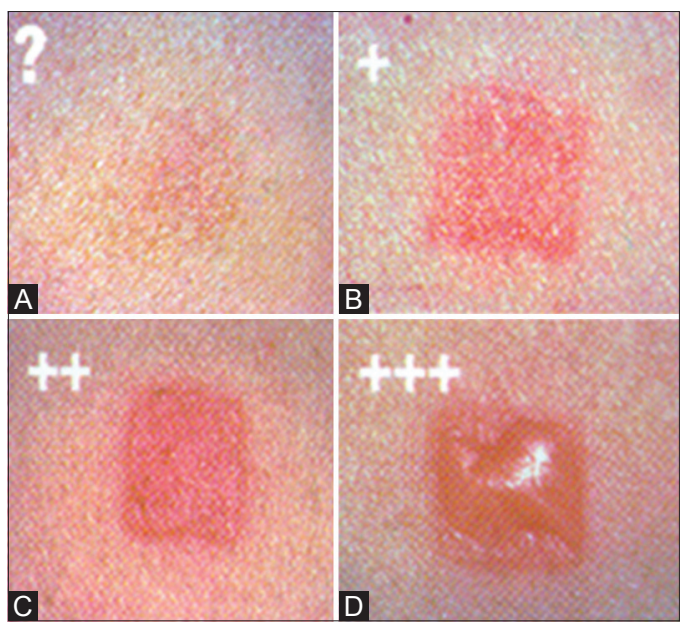

FIGURE 1. Interpretation of patch testing. (A) uncertain reaction; (B) weak positive reaction; (C)strong positive reaction; (D) extreme positive reaction.

regression was used to assess the association between contact dermatitis and other variables. Odds ratio (OR) and 95\% confidence interval (CI) are reported. All the tests were two-sided and statistical significance was defined as $\mathrm{p} \leq 0.05$.

\section{RESULTS}

\section{Characteristics of patients with contact dermatitis}

In total, 193 patients clinically suspected for CD and underwent PT. The mean age of the study population was 40.1 years $( \pm 10.5$ years), with the youngest age of 9 years and the oldest of 62 years. The mean age of females and males was the same with no significant difference $(t=0.381, \mathrm{p}=0.7)$.

Socio-demographic characteristics of the patients included in the study are presented in Table 1. From all the patients included, 86 (46.4\%) were male and $107(53.6 \%)$ were female, with no significant difference between gender $\left(\mathrm{X}^{2}=2.07\right.$, $\mathrm{p}=0.1)$. Most of the patients were in the age-group of 31-40 years (63 patients). All the other agegroups had a significant lower number of patients. According to the place of residence, the number of patients from urban areas was significantly higher than those who lived in rural areas $\left(\mathrm{X}^{2}=62.6, \mathrm{p}<\right.$ $0.01)$. Construction workers were most affected by contact dermatitis (21.8\%) followed by hairdressers (9.8\%).
TABLE 1. Socio-demographic characteristics of the patients involved in the study

\begin{tabular}{|c|c|c|c|}
\hline Socio-demographic characteristics & $\mathrm{N}$ & $(\%)$ & $p$-value \\
\hline Gender & & & 0.1 \\
\hline Male & 86 & 46.4 & \\
\hline Female & 107 & 53.6 & \\
\hline Age-group (years) & & & $<0.01$ \\
\hline $0-10$ & 2 & 1.0 & \\
\hline $11-20$ & 2 & 1.0 & \\
\hline $21-30$ & 40 & 20.7 & \\
\hline $31-40$ & 63 & 32.6 & \\
\hline $41-50$ & 46 & 23.8 & \\
\hline $51-60$ & 39 & 20.2 & \\
\hline $60+$ & 1 & 0.5 & \\
\hline Residence & & & $<0.01$ \\
\hline Rural & 41 & 21.2 & \\
\hline Urban & 152 & 79 & \\
\hline Profession & & & $<0.01$ \\
\hline Constructor worker & 42 & 21.8 & \\
\hline Hairdresser & 19 & 9.8 & \\
\hline Employee & 14 & 7.3 & \\
\hline Domestic & 13 & 6.7 & \\
\hline Seller & 12 & 6.2 & \\
\hline Cashier & 11 & 5.7 & \\
\hline Dentist & 10 & 5.2 & \\
\hline Physician & 9 & 4.7 & \\
\hline Driver & 9 & 4.7 & \\
\hline Nurse & 8 & 4.1 & \\
\hline Student & 8 & 4.1 & \\
\hline Bartender & 6 & 3.1 & \\
\hline Laboratory technician & 6 & 3.1 & \\
\hline Engineer & 4 & 2.1 & \\
\hline Pupil & 4 & 2.1 & \\
\hline Telephone operator & 3 & 1.6 & \\
\hline Sanitary & 3 & 1.6 & \\
\hline Veterinarian & 3 & 1.6 & \\
\hline Teacher & 2 & 1.0 & \\
\hline Artist & 2 & 1.0 & \\
\hline Pharmacist & 2 & 1.0 & \\
\hline Journalist & 2 & 1.0 & \\
\hline Social worker & 1 & 0.5 & \\
\hline
\end{tabular}

\section{The results of the patch testing}

Positive PT results with at least one allergen were seen in 144 patients $(74.6 \%)$. This was significantly higher compared to 49 patients $(25.4 \%)$ who had a negative PT result $\left(\mathrm{X}^{2}=45.7 ; \mathrm{p}<0.01\right)$. Table 2 shows the results of the PT according to gender and 
TABLE 2. The results of patch testing according to gender and age-groups

\begin{tabular}{|c|c|c|c|}
\hline Patch test results & $\mathrm{N}$ & $(\%)$ & $p$-value \\
\hline Patch test & & & $<0.01$ \\
\hline Negative & 49 & 25.4 & \\
\hline Positive & 144 & 74.6 & \\
\hline Females & & & $<0.01$ \\
\hline Negative & 22 & 11 & \\
\hline Positive & 85 & 44 & \\
\hline Males & & & $<0.01$ \\
\hline Negative & 27 & 14 & \\
\hline Positive & 59 & 31 & \\
\hline \multirow[t]{2}{*}{ Age-group } & \multicolumn{3}{|c|}{$\mathrm{N}(\%)$} \\
\hline & Negative & & Positive \\
\hline $0-10$ & $1(50)$ & & $1(50)$ \\
\hline $11-20$ & $0(0)$ & & $2(100)$ \\
\hline $21-30$ & $10(25)$ & & $30(75)$ \\
\hline $31-40$ & $18(29)$ & & $45(71)$ \\
\hline $41-50$ & $10(22)$ & & $36(78)$ \\
\hline $51-60$ & $10(26)$ & & $29(74)$ \\
\hline $60+$ & $0(0)$ & & $1(100)$ \\
\hline
\end{tabular}

age-groups. Female patients had 1.8 times higher chances for having a positive patch test result compare to male patients $(\mathrm{OR}=1.8 ; 95 \% \mathrm{CI}, 0.91-$ 3.39), but the statistical significance was not reached $\left(X^{2}=2.4, \mathrm{p}=0.08\right)$.

Except the age group $0-10$ years, the positivity of PT was dominant in all age groups and with a significant difference compared to patients with negative results $(\mathrm{p}<0.05)$. PT results according to profession are presented in Figure 2.

Besides teachers, artists, journalists, social workers and students, all the other professions had a significantly higher percentage of positive results ( $\mathrm{p}<0.05)$. The average percentage of positivity according to profession was $75.3 \%, \mathrm{SD} \pm 20.5$. From all patients who applied PT, 144 of them (75\%) resulted positive to one or more allergens. From these 144 patients, $30(21 \%)$ were positive for more than 2 allergens (Figure 3 ).

Nickel (14.1\%) and potassium dichromate (12.6\%) were the two most common allergens to which patients resulted positive, followed by mix perfume (7.5\%) and cobalt (7\%). Figure 4 shows the percentage of allergens that resulted positive after PT of patients with CD.

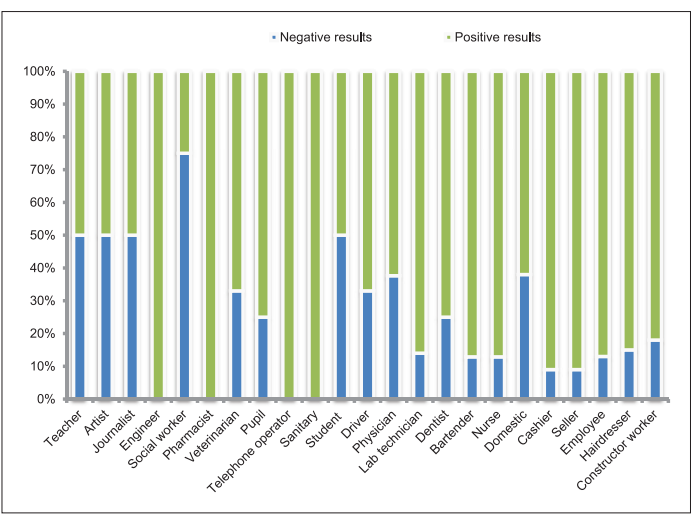

FIGURE 2. Patch testing results according to profession

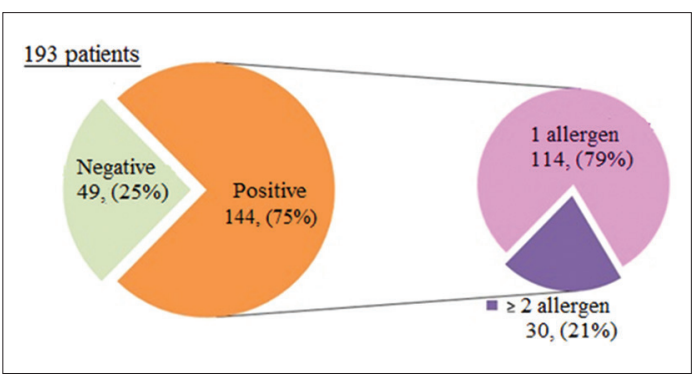

FIGURE 3. The distribution of cases by positivity to allergens

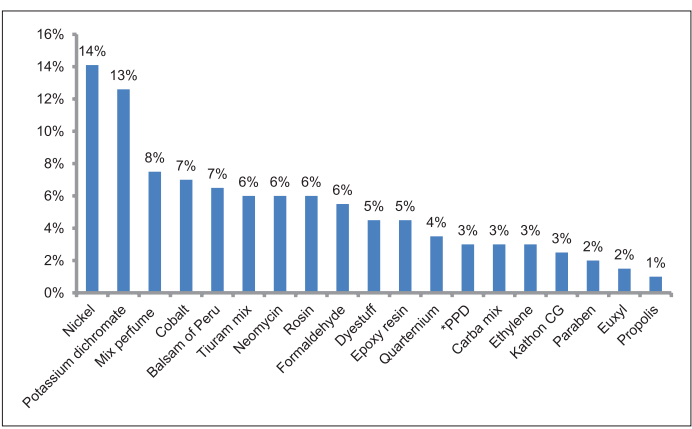

FIGURE 4. The percentage of allergens that resulted positive after patch testing of patients with $C D$

\section{DISCUSSION}

In this study we evaluated the use of PT for the diagnosis of $\mathrm{CD}$ and provided current data on the frequency of sensitization to various contact allergens. Furthermore, we evaluated the distribution of risk factors (age, gender, occupation and place of residence) in a group of Albanian patients. The average age of the study population was 40.1 years 
$( \pm 10.5$ years), which is approximately the same value reported in the literature $(14,15,20)$. We included in total 193 patients, 86 male and 107 female. The number of women who performed PT was higher than the number of men. However, we found no significant difference between gender $(\mathrm{p}=0.1)$. The sensibility of women to skin diseases in general and to this pathology in particular, leads them to the immediate application of patch tests. Whereas, the large number of men clinically diagnosed with the same pathology hesitate to undergo the procedure of patch testing. This correlates with the lifestyle and education in our region. Nevertheless, studies report that hand eczema is much more frequent in women and the impact of disease is larger in women than in men $(15,21)$.

The highest prevalence of contact dermatitis was noticed in the age-group of 31-40 years (63 patients), with significant difference with other age-groups $(\mathrm{p}<0.01)$. A simple explanation of this result could be the fact that people of this age-group have a higher frequency of exposure to allergens due to lifestyle and work activity $(14,15,20,22)$.

According to the place of residence, the number of patients who lived in urban areas (153 patients) was significantly higher than those who lived in rural areas (41 patients). Most of the professions that are exposed to multiple allergens are applied in the cities, while in rural areas the number of these professions is limited. Also in Albania, the access to primary health services and specialized medical help is higher in urban areas compared to rural ones. Furthermore, the education level is higher in urban areas and people tend to seek medical assistance earlier and more often.

Construction workers were most affected by contact dermatitis followed by hairdressers. All the other professions were significantly in low number. Construction workers have very tight and longterm contact with different substances, especially with potassium dichromate, nickel and cobalt and epoxy resin (23-25). Moreover, the non-use of protective gloves or emollient creams to protect the skin increases the risk for the contact dermatitis $(26,27)$. Likewise, hairdressers have a high number of substances to which they are exposed, including agents of cosmetic products (mix perfume, balsam of Peru) and hair color products ( $\mathrm{p}$-phenylenediamine which is known as PPD) $(22,28,29)$ Also, the use of plastic gloves from hairdressers exposes their skin to further allergens, such as Latex or Thiuram Mix $(30,31)$.

After patch testing, the two most common allergens that resulted positive in most of the patients were nickel and potassium dichromate, followed by mix perfume and cobalt. A recent study of the Odense Adolescence Cohort has reported that the most common contact allergen among young Danish adults is nickel (11.8\%), followed by cobalt $(2.3 \%)$ and PPD (1.1\%) (32). Likewise, nickel has been reported as the most common allergen in a lot of other studies (33-35). Previous studies have reported that contact allergy to nickel and cobalt is more common in women than men (14). The higher prevalence among women is explained with the often and closed contact with objects containing nickel and/or cobalt, especially with jewelries and/or piercing which women start to use since early in life (36). The wide spread of nickel sulphate in our everyday life (in sunglasses frame, door handles, spoons and forks in the kitchen, medical instruments, dental materials, metal chair and as well as ingredient in a lot of food products) explains the high prevalence of positive patch tests to this substance compared to other allergens less common in everyday life $(37,38)$. Besides industrial materials (cement, mortar, plaster, bricks), potassium dichromate is also common in everyday life and can be found in leather clothing, shoes, colored gloves, matches and tattoos $(24,34,38)$. Moreover, potassium dichromate is found in orthopedic prostheses and dental implants, posing so to a high risk people who are not aware of being sensitive to this substance (39).

The daily increase of using chemical, aromatic and cosmetic products has also increased the number of allergies to certain substances such are mix perfume, balsam of Peru and PPD $(22,29,33,40)$. In our study, mix perfume is the third most common allergen to which contact dermatitis patients had a positive patch test. This result was expected since most of our patients were female and mix perfume is found in all aromatized cosmetic products. Half of the patients positive to mix perfume were also positive to balsam of Peru, which is also part of aromatized cosmetic products. Likewise, balsam of Peru is found as an aromatic component in different kinds of food, drinks, deserts and syrups (41). 
Another important allergen that should be discussed is formaldehyde. Formaldehyde and other substances released from it are the most frequently preservatives on the market (42). Due to the wide spread, formaldehyde is difficult to be avoided, even in small amounts. This is the reason why new clothes should always be washed before wearing and places were smoke is allowed should be ventilated. It is recommended to use cotton clothes and cosmetic products with a concentration of formaldehyde below $0.2 \%$ (43).

\section{CONCLUSION}

In Albanian population, construction workers and hairdressers are most affected from contact dermatitis. The most common allergens are nickel, potassium dichromate and mix perfume. Determination of allergens that cause contact dermatitis is necessary not only to confirm the diagnosis, but also for the qualitative treatment and prevention of the disease. This study reemphasizes that patch testing, even though an old method still remains a valuable and non-invasive approach to determine the causes of contact dermatitis.

\section{CONFLICT OF INTEREST}

The authors declare that they have no competing interests.

\section{REFERENCES}

1. Boverhof DR, Ladics G, Luebke B, Botham J, Corsini E, Evans E, et al. Approaches and considerations for the assessment of immunotoxicity for environmental chemicals: a workshop summary. Regul Toxicol Pharmacol. 2014 Feb;68(1):96-107. http://dx.doi.org/10.1016/j.yrtph.2013.11.012

2. Wold L, Chen JK, Lampel HP. Hand dermatitis: an allergist's nightmare. Curr Allergy Asthma Rep. 2014 Nov;14(11):474. http://dx.doi.org/10.1007/ s11882-014-0474-0

3. Kouris A, Armyra K, Christodoulou C, Katoulis A, Potouridou I, Tsatovidou R, et al. Quality of life, anxiety, depression and obsessive-compulsive tendencies in patients with chronic hand eczema. Contact Dermatitis. 2015 Jun;72(6):367-70. http://dx.doi.org/10.1111/cod.12366

4. Lau MY, Burgess JA, Nixon R, Dharmage SC, Matheson MC. A review of the impact of occupational contact dermatitis on quality of life. J Allergy (Cairo). 2011;2011:964509. http://dx.doi.org/10.1155/2011/964509

5. Brutti CS, Bonamigo RR, Cappelletti T, Martins-Costa GM, Menegat AP. Occupational and non-occupational allergic contact dermatitis and quality of life: a prospective study. An Bras Dermatol. 2013 Jul-Aug;88(4):670-1. http://dx.doi.org/10.1590/abd1806-4841.20131950

6. Peng W, Novak N. Pathogenesis of atopic dermatitis. Clin Exp Allergy. 2015 Mar;45(3):566-74. http://dx.doi.org/10.1111/cea.12495

7. Ale IS, Maibacht HA. Diagnostic approach in allergic and irritant contact dermatitis. Expert Rev Clin Immunol. 2010 Mar;6(2):291-310. http://dx.doi. org/10.1586/eci.10.4

8. Apfelbacher CJ, Soder S, Diepgen TL, Weisshaar E. The impact of measures for secondary individual prevention of work-related skin diseases in health care workers: 1 -year follow-up study. Contact Dermatitis. 2009 Mar;60(3):144-9. http://dx.doi.org/10.1111/j.1600-0536.2008.01505.x

9. Fall S, Bruze M, Isaksson M, Liden C, Matura M, Stenberg B, et al. Contact allergy trends in Sweden - a retrospective comparison of patch test data from 1992, 2000, and 2009. Contact Dermatitis. 2015 May;72(5):297-304. http://dx.doi.org/10.1111/cod.12346

10. Diepgen TL, Andersen KE, Chosidow O, Coenraads PJ, Elsner P, English J, et al. Guidelines for diagnosis, prevention and treatment of hand eczema. J Dtsch Dermatol Ges. 2015 Jan;13(1):e1-22. http://dx.doi. org/10.1111/ddg.12510_1

11. Kimber I, Travis MA, Martin SF, Dearman RJ. Immunoregulation of skin sensitization and regulatory T cells. Contact Dermatitis. 2012 Oct;67(4):179-83. http://dx.doi.org/10.1111/j.1600-0536.2012.02148.x

12. Fonacier L, Bernstein DI, Pacheco K, Holness DL, Blessing-Moore J, KhanD, et al. Contact dermatitis: a practice parameter-update 2015 J Allergy Clin Immunol Pract. 2015 May-Jun;3(3 Suppl):S1-S39. http:// dx.doi.org/10.1016/j.jaip.2015.02.009

13. Dickel H, Kreft B, Geier J. Strip patch testing does not affect reaction profiles of standard allergens. Contact Dermatitis. $2015 \mathrm{Jul} ; 73(1): 36-43$. http:// dx.doi.org/10.1111/cod.12384

14. Thyssen JP, Linneberg A, Menne T, Johansen JD. The epidemiology of contact allergy in the general population--prevalence and main findings. Contact Dermatitis. 2007 Nov;57(5):287-99. http://dx.doi. org/10.1111/j.1600-0536.2007.01220.x

15. Thyssen JP, Johansen JD, Linneberg A, Menne T. The epidemiology of hand eczema in the general population--prevalence and main findings. Contact Dermatitis. 2010 Feb;62(2):75-87. http://dx.doi. org/10.1111/j.1600-0536.2009.01669.x

16. Turner S, Carder M, van Tongeren M, McNamee R, Lines S, Hussey L, et al. The incidence of occupational skin disease as reported to The Health and Occupation Reporting (THOR) network between 2002 and 2005. Br J Dermatol. 2007 Oct;157(4):713-22. http://dx.doi. org/10.1111/j.1365-2133.2007.08045.x

17. Pesonen M, Jolanki R, Larese Filon F, Wilkinson M, Krecisz B, KiecSwierczynska M, et al. Patch test results of the European baseline series among patients with occupational contact dermatitis across Europe - analyses of the European Surveillance System on Contact Allergy network, 2002-2010. Contact Dermatitis. 2015 Mar;72(3):154-63. http://dx.doi. org/10.1111/cod.12333

18. Susitaival P, Flyvholm MA, Meding B, Kanerva L, Lindberg M, Svensson A, et al. Nordic Occupational Skin Questionnaire (NOSQ-2002): a new tool for surveying occupational skin diseases and exposure. Contact Dermatitis. 2003 Aug;49(2):70-6. http://dx.doi.org/10.1111/j.0105-1873.2003.00159.x

19. Reduta T, Bacharewicz J, Pawlos A. Patch test results in patients with allergic contact dermatitis in the Podlasie region. Postepy Dermatol Alergol. 2013 Dec;30(6):350-7. http://dx.doi.org/10.5114/pdia.2013.39433

20. Uter W, Gefeller O, Gimenez-Arnau A, Frosch P, Duus Johansen J, Schuttelaar ML, et al. Characteristics of patients patch tested in the European Surveillance System on Contact Allergies (ESSCA) network, 2009-2012. Contact Dermatitis. 2015 May 13. http://dx.doi.org/10.1111/ cod. 12409

21. Mollerup A, Veien NK, Johansen JD. An analysis of gender differences in patients with hand eczema - everyday exposures, severity, and consequences. Contact Dermatitis. 2014 Jul;71(1):21-30. http://dx.doi. org/10.1111/cod.12206

22. Kumar P, Paulose R. Patch testing in suspected allergic contact dermatitis to cosmetics. Dermatol Res Pract. 2014;2014:695387. http://dx.doi. org/10.1155/2014/695387

23. Prodi A, Rui F, Fortina AB, Corradin MT, Filon FL. Occupational 
sensitization to epoxy resins in Northeastern Italy (1996-2010). Int J Occup Environ Health. 2015 Jan;21(1):82-7. http://dx.doi.org/10.1179/20493967 14Y.0000000095

24. Schwensen JF, Menne T, Veien NK, Funding AT, Avnstorp C, Osterballe M, et al. Occupational contact dermatitis in blue-collar workers: results from a multicentre study from the Danish Contact Dermatitis Group (2003-2012). Contact Dermatitis. 2014 Dec;71(6):348-55. http://dx.doi.org/10.1111/ cod. 12277

25. Uter W, Gefeller O, Geier J, Schnuch A. Contact sensitization to cobalt--multifactorial analysis of risk factors based on long-term data of the Information Network of Departments of Dermatology. Contact Dermatitis. 2014 Dec;71(6):326-37. http://dx.doi.org/10.1111/cod.12284

26. Timmerman JG, Zilaout $H$, Heederik D, Spee T, Smit LA. Validation of a questionnaire on hand hygiene in the construction industry. Ann Occup Hyg. 2014 Oct;58(8):1046-56. http://dx.doi.org/10.1093/annhyg/meu053

27. Del Rosso JQ. Incorporation of a barrier protection cream in the management of chronic hand dermatitis: focus on data supporting an established hand protectant formulation and modifications designed to assist in barrier repair. J Clin Aesthet Dermatol. 2014 Feb;7(2):40-8.

28. Hougaard MG, Winther L, Sosted H, Zachariae C, Johansen JD. Occupational skin diseases in hairdressing apprentices - has anything changed? Contact Dermatitis. 2015 Jan;72(1):40-6. http://dx.doi. org/10.1111/cod. 12315

29. Vogel TA, Coenraads PJ, Bijkersma LM, Vermeulen KM, Schuttelaar ML. p-Phenylenediamine exposure in real life - a case-control study on sensitization rate, mode and elicitation reactions in the northern Netherlands. Contact Dermatitis. 2015 Jun;72(6):355-61. http://dx.doi.org/10.1111/cod.12354

30. Antelmi A, Young E, Svedman C, Zimerson E, Engfeldt M, Foti C, et al. Are gloves sufficiently protective when hairdressers are exposed to permanent hair dyes? An in vivo study. Contact Dermatitis. 2015 Apr;72(4):229-36. http://dx.doi.org/10.1111/cod.12320

31. Boonchai W, Sirikudta W, lamtharachai P, Kasemsarn P. Latex glove-related symptoms among health care workers: a self-report questionnaire-based survey. Dermatitis. 2014 May-Jun;25(3):135-9. http://dx.doi. org/10.1097/DER.00000000000000044

32. Mortz CG, Bindslev-Jensen C, Andersen KE. Prevalence, incidence rates and persistence of contact allergy and allergic contact dermatitis in The Odense Adolescence Cohort Study: a 15-year follow-up. Br J Dermatol.

\section{Feb;168(2):318-25. http://dx.doi.org/10.1111/bjd.12065}

33. Belloni Fortina A, Cooper SM, Spiewak R, Fontana E, Schnuch A, Uter W. Patch test results in children and adolescents across Europe Analysis of the ESSCA Network feminine 2002-2010. Pediatr Allergy Immunol. 2015 May 5. http://dx.doi.org/10.1111/pai.12397

34. Boonchai W, Thanomkitti K, Kasemsarn P. Occupational contact dermatitis in tertiary university hospital: a 5-year retrospective study. J Med Assoc Thai. 2014 Nov;97(11):1182-8.

35. Borowska S, Brzoska MM. Metals in cosmetics: implications for human health. J Appl Toxicol. 2015 Jun;35(6):551-72. http://dx.doi.org/10.1002/ jat.3129

36. Warshaw EM, Kingsley-Loso JL, DeKoven JG, Belsito DV, Zug KA, Zirwas MJ, et al. Body piercing and metal allergic contact sensitivity: North American contact dermatitis group data from 2007 to 2010. Dermatitis. $2014 \quad$ Sep-Oct;25(5):255-64. http://dx.doi.org/10.1097/ DER.0000000000000066

37. Golz L, Papageorgiou SN, Jager A. Nickel hypersensitivity and orthodontic treatment: a systematic review and meta-analysis. Contact Dermatitis. 2015 Jul;73(1):1-14. http://dx.doi.org/10.1111/cod.12392

38. Turcic P, Marinovic Kulisic S, Lipozencic J. Patch test reactions to metal salts in patients with different types of dermatitis. Acta Dermatovenerol Croat. 2013;21(3):180-4.

39. Castanedo-Tardan MP, Jacob SE. Potassium dichromate. Dermatitis. 2008 Jul-Aug;19(4):E24-5.

40. Goldenberg A, Jacob SE. Paraphenylenediamine in black henna temporary tattoos: 12-year Food and Drug Administration data on incidence, symptoms, and outcomes. J Am Acad Dermatol. 2015 Apr;72(4):724-6. http://dx.doi.org/10.1016/j.jaad.2014.11.031

41. Warshaw EM, Botto NC, Zug KA, Belsito DV, Maibach HI, Sasseville D, et al. Contact dermatitis associated with food: retrospective cross-sectional analysis of North American Contact Dermatitis Group data, 2001-2004. Dermatitis. 2008 Sep-Oct; 19(5):252-60.

42. Yim E, Baquerizo Nole KL, Tosti A. Contact dermatitis caused by preservatives. Dermatitis. 2014 Sep-Oct;25(5):215-31. http://dx.doi.org/10.1097/ DER.0000000000000061

43. Ponten A, Bruze M. Formaldehyde. Dermatitis. 2015 Jan-Feb;26(1):3-6. http://dx.doi.org/10.1097/DER.0000000000000075 